\title{
KSR modulates signal propagation within the MAPK cascade
}

\author{
Marc Therrien,, ${ }^{1}$ Neil R. Michaud, ${ }^{2}$ Gerald M. Rubin, ${ }^{1}$ and Deborah K. Morrison ${ }^{2}$ \\ Howard Hughes Medical Institute, Department of Molecular and Cell Biology, University of California at Berkeley, \\ Berkeley, California 94720-3200 USA; ${ }^{2}$ Molecular Basis of Carcinogenesis Laboratory, ABL-Basic Research Program, \\ National Cancer Institute, Frederick Cancer Research and Development Center, Frederick, Maryland 21702 USA
}

\begin{abstract}
Kinase suppressor of Ras (KSR) is a recently identified component of Ras-dependent signaling pathways. In this report, we show that murine KSR1 (mKSR1) cooperates with activated Ras to promote Xenopus oocyte maturation and cellular transformation and provide evidence that this cooperation occurs by accelerating mitogen and extracellular regulated kinase (MEK) and mitogen-activated protein kinase (MAPK) activation. We also find that mKSR1 associates with Raf-1 at the plasma membrane in a Ras-dependent manner, indicating the presence of a membrane-bound kinase signaling complex. Although mKSR1 is related structurally to Raf-1, our findings reveal striking functional differences between these proteins. In marked contrast to the isolated amino- and carboxy-terminal domains of Raf-1, the KSR amino terminus also cooperates with Ras, whereas the carboxy-terminal kinase domain blocks Ras signaling as well as MEK and MAPK activation. The isolated KSR kinase domain suppressed Xenopus oocyte maturation, cellular transformation, and Drosophila eye development, suggesting that separation of the amino- and carboxy-terminal domains has uncoupled the normal regulation of KSR as a positive effector of Ras signaling. Together, our findings indicate that mKSR1 is an integral component of the MAPK module functioning via a novel mechanism to modulate signal propagation between Raf-1, MEK1, and MAPK.
\end{abstract}

[Key Words: KSR; MAPK; MEK; Raf; Ras; signal transduction]

Received August 1, 1996; revised version accepted September 9, 1996.

Ras plays a central role in the transmission of proliferative and differentiative signals elicited by receptor tyrosine kinases (RTKs). A major route by which Ras-mediated signals are transduced from the plasma membrane to the nucleus involves the mitogen-activated protein kinase (MAPK) module (for review, see Marshall 1995). This module is composed of at least three kinases, Raf-1, MEK1 (MAPK kinase), and MAPK, which function to transmit cellular signals through a phosphorylation cascade. The current model proposes that upon Ras activation, Raf- 1 is recruited to the plasma membrane by a direct association with Ras. Once at the membrane, Raf- 1 becomes activated and promotes signal propagation by the sequential activation of MEK1 and MAPK (for review, see Moodie and Wolfman 1994). Activated MAPK then phosphorylates critical cytoplasmic and nuclear substrates, thereby regulating their activity and orchestrating a specific cellular response (for review, see Waskiewicz and Cooper 1995; Treisman 1996).

Although this linear pathway provides a coherent model for how RTK-mediated signals are propagated from Ras to the nucleus, there are several important aspects of this process that remain to be resolved. In particular, the precise mechanism by which Raf-1 becomes activated at the membrane is unclear (Leevers et al. 1994; Stokoe et al. 1994). In addition, the mechanisms that provide signal specificity or that are required for signal termination within the MAPK module are largely unknown. Furthermore, other Ras-dependent pathways, in addition to the MAPK module, appear to be required for mitogenic and differentiative responses (Cowley et al. 1994; White et al. 1995). The recent identification of other putative Ras effectors, such as the phosphatidylinositol 3-kinase and RAL-guanine nucleotide dissociation stimulator (Hofer et al. 1994; Rodriguez-Viciana et al. 1994; Spaargaren and Bischof 1994), further indicates that Ras controls multiple pathways and suggests that a complex network of interactions among different pathways is required to mediate the biological effects of Ras.

Recently, in a genetic screen for downstream effectors of Ras in Drosophila, a novel kinase named kinase suppressor of Ras (KSR) was isolated (Therrien et al. 1995). Loss-of-function $k s r$ alleles were recovered as dominant suppressors of a rough eye phenotype induced by an activated Ras 1 allele. In Drosophila, KSR was found to be required for cell proliferation and/or survival and to act in at least two separate RTK pathways, the Sevenless (Sev) and Torso (Tor) pathways. A homolog of KSR was also isolated in $C$. elegans using two similar genetic screens for suppressors of activated Ras (Kornfeld et al. 1995; Sundaram and Han 1995). These genetic studies and the isolation of mammalian homologs of KSR (Ther- 
A
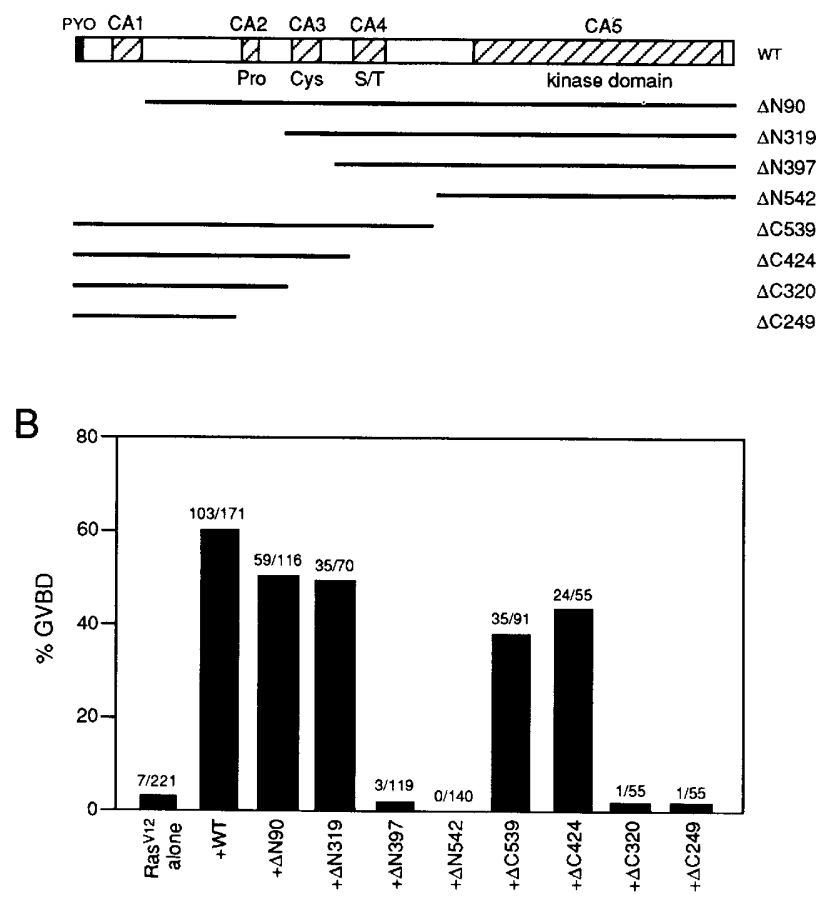

C

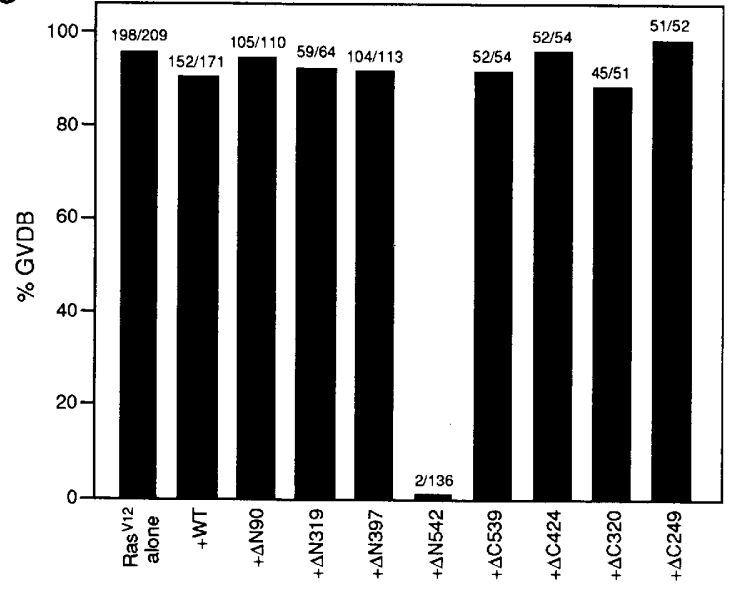

rien et al. 1995) suggested that KSR is a general component of Ras-dependent signaling pathways with an evolutionarily conserved function. The KSR members define a novel family of kinases that, although distinct, are related in sequence to the Raf kinase family. The precise role of KSR in signal transduction was not elucidated by the genetic studies; however, Drosophila epistasis experiments did position KSR to function either upstream of or parallel to Raf (Therrien et al. 1995). These results led to the speculation that KSR might be a kinase involved in the Raf activation process or a kinase acting in a pathway parallel to the MAPK module.

To further address the role of KSR in Ras signaling, we initiated a functional characterization of a murine KSR homolog (mKSR1). In this report, we show that mKSR1 cooperates with Ras to enhance its biological effects and
Figure 1. Effect of mKSR1 deletion mutants on Ha-Ras ${ }^{\mathrm{V} 12}$-induced Xenopus oocyte maturation. (A) Schematic representation of the WT and the amino-terminal $(\Delta N)$ or carboxy-terminal $(\Delta C)$ mKSR1 deletion mutant proteins. The full-length 873 amino acid $\mathrm{mKSR} 1$ protein $(\mathrm{WT})$ is depicted. The hatched boxes represent the five conserved areas (CAl-CA5) of the KSR family members (Therrien et al. 1995). Pro, Cys, and S/T indicate that the corresponding CA regions are rich in proline, cysteine, or serine/threonine residues, respectively. The portion of mKSR 1 left intact for each of the deletion mutants is indicated by a black line. The number following $\Delta \mathrm{N}$ or $\Delta \mathrm{C}$ indicates the position of the first or last natural amino acid, respectively, found in the corresponding mKSR1 deletion mutant. In addition, the Pyo epitope tag (solid box) was inserted eight amino acids downstream of the first methionine in each construct. $(B)$ Induction of Xenopus oocyte meiotic maturation by the expression of Ha$\mathrm{Ras}^{\mathrm{V} 12}$ alone or by the coexpression of Ha-Ras ${ }^{\mathrm{V} 12}$ with mKSR1 proteins. Buffer or RNA ( $\sim 30 \mathrm{ng})$ encoding $\mathrm{WT}, \Delta \mathrm{N}$, or $\Delta \mathrm{C}$ proteins was injected into defolliculated stage VI oocytes. After 8-12 hr, the oocytes were injected with Ha-Ras ${ }^{\mathrm{V} 12}$ RNA. GVBD was scored when $3 \%$ of the oocytes expressing Ha-Ras ${ }^{\mathrm{V} 12}$ alone had undergone GVBD. The percentage of oocytes undergoing GVBD is expressed as a solid bar and the ratio of the number of oocytes undergoing GVBD to the total number injected is displayed above each bar. The numbers obtained represent a compilation of at least three independent experiments where equivalent amounts of the KSR mutant and $\mathrm{Ha}-\mathrm{Ras}^{\mathrm{V} 12}$ proteins were expressed. $|C|$ Same as in $B$ except GVBD was scored when $90-100 \%$ of the oocytes expressing Ha-Ras ${ }^{\mathrm{V} 12}$ alone had undergone GVBD.

that the mKSR1 function itself is regulated by Ras. In addition, analysis of a series of mKSRl deletion mutants revealed unexpected behaviors for both the amino-terminal and the carboxy-terminal domains. Expression of the amino-terminal domain cooperated with oncogenic Ras, although less efficiently than full-length mKSR1, to promote Xenopus oocyte maturation and cellular transformation. The cooperative effect of $\mathrm{mKSR} 1$ required the cysteine-rich CA3 region and resulted in an accelerated activation of MEK1 and MAPK. In contrast, expression of the isolated carboxy-terminal kinase domain efficiently blocked Ras-dependent Xenopus oocyte maturation, cellular transformation, and Drosophila eye development. The isolated mKSRl kinase domain prevented MEK1 and MAPK activation but did not inhibit Raf-1 activation. Finally, we demonstrate an in vivo associa- 
tion between mKSR 1 and Raf- 1 that is Ras-dependent, occurs at the plasma membrane, and involves the mKSRl kinase domain. Together, these findings suggest that $\mathrm{mKSR} 1$ is a component of the MAPK cascade whose function is to regulate signal propagation between Raf-1, MEK1, and MAPK.

\section{Results \\ Effect of mKSR1 on Ras-mediated Xenopus oocyte maturation}

To examine the biological function of $\mathrm{mKSR} 1$, we constructed a series of amino- and carboxy-terminal deletion mutants with each of the conserved domains of mKSR 1 sequentially removed (Fig. 1A). The mKSR1 deletion mutants were then expressed in stage VI-arrested Xenopus oocytes and their effect on oocyte maturation was evaluated. Xenopus oocytes were chosen for this analysis because this system has been used previously to identify activated and dominant-inhibitory mutants of other components of the Ras/Raf-1/MAPK pathway (Birchmeier et al. 1985; Fabian et al. 1993). In these studies, none of the mKSRl proteins induced oocyte maturation when expressed individually (data not shown). However, expression of the wild-type (WT) and several of the deletion mutants markedly accelerated oocyte maturation induced by an activated form of Ras, Ha-Ras ${ }^{\mathrm{V} 12}$. At time points when only $3 \%$ of the Ha-Ras ${ }^{\mathrm{V} 12}$-injected oocytes had undergone maturation, as evidenced by germinal vesicle breakdown $(\mathrm{GVBD}),>60 \%$ of the oocytes coexpressing WT and $>50 \%$ coexpressing the amino-terminal deletion mutants, $\Delta N 90$ and $\Delta N 319$, had undergone GVBD (Fig. 1B). Expression of two of the carboxy-terminal deletion mutants, $\Delta \mathrm{C} 539$ and $\Delta \mathrm{C} 424$, also cooperated with $\mathrm{Ha}-\mathrm{Ras}^{\mathrm{V} 12}$ to induce GVBD in $38 \%$ and $44 \%$ of the oocytes, respectively (Fig. 1B). The failure of $\Delta$ N397, $\Delta \mathrm{C} 249$, and $\Delta \mathrm{C} 320$ to cooperate with Ha-Ras ${ }^{\mathrm{V} 12}$ indicates that sequences localized in the CA3 cysteine-rich region are involved in the enhancing effect. However, the kinase domain of mKSRl was required for maximal cooperativity in that WT was the most augmenting protein and the induction of maturation occured first in oocytes coexpressing WT (Fig. 5A).

In contrast to the augmentation of Ha-Ras ${ }^{\mathrm{V} 12}$-induced oocyte maturation observed at early time points, examination of the maturation levels, when $90-100 \%$ of the $\mathrm{Ha}-\mathrm{Ras}^{\mathrm{V} 12}$-injected oocytes had undergone GVBD, revealed that expression of $\Delta \mathrm{N} 542$, encoding the catalytic domain of mKSR1, efficiently blocked Ha-Ras ${ }^{\mathrm{V} 12}$-induced maturation (Fig. 1C). Surprisingly, these findings suggest that the isolated kinase domain of mKSRl acts in a dominant-inhibitory manner to block Ras-mediated signaling.

Effect of mKSR1 on Ha-Ras ${ }^{V 12}$-induced transformation in mammalian cells

To examine whether mKSRl would affect Ras-mediated transformation in mammalian cells, we cotransfected
Balb/3T3 cells with plasmids encoding Ha-Ras ${ }^{\mathrm{V} 12}$ and either WT, $\Delta \mathrm{C} 539$, or $\Delta \mathrm{N} 542$. After 3 weeks, the cells were evalutated for focus formation. Expression of WT or $\Delta \mathrm{C} 539$ increased the number of $\mathrm{Ha}-\mathrm{Ras}^{\mathrm{V} 12}$-induced foci (7- to 10-fold and two-fold, respectively), whereas expression of $\Delta \mathrm{N} 542$ blocked Ha-Ras ${ }^{\mathrm{V} 12}$-induced focus formation (Fig. 2). These results are consistent with the findings observed in the oocyte maturation assays in that both WT and the isolated amino-terminal domain of mKSRl cooperated with Ha-Ras ${ }^{\mathrm{V} 12}$. As was also observed in oocytes, WT was the most effective protein in augmenting $\mathrm{Ha}-\mathrm{Ras}^{\mathrm{V} 12}$ activity, confirming that the $\mathrm{ki}$ nase domain of mKSR1 is required for maximal cooperativity. In addition, the isolated carboxy-terminal catalytic domain again acted in a dominant-inhibitory manner to block Ras-mediated signaling, suggesting that the separation of the amino- and carboxy-terminal domains has uncoupled the normal regulation of mKSR1 as a positive effector of Ras signaling.

\section{Effect of mKSR1 on Xenopus oocyte maturation induced by Ras-dependent and Ras-independent activators}

To determine whether mKSRl activity was Ras-dependent, we examined the effect that $\mathrm{mKSR} 1$ expression had

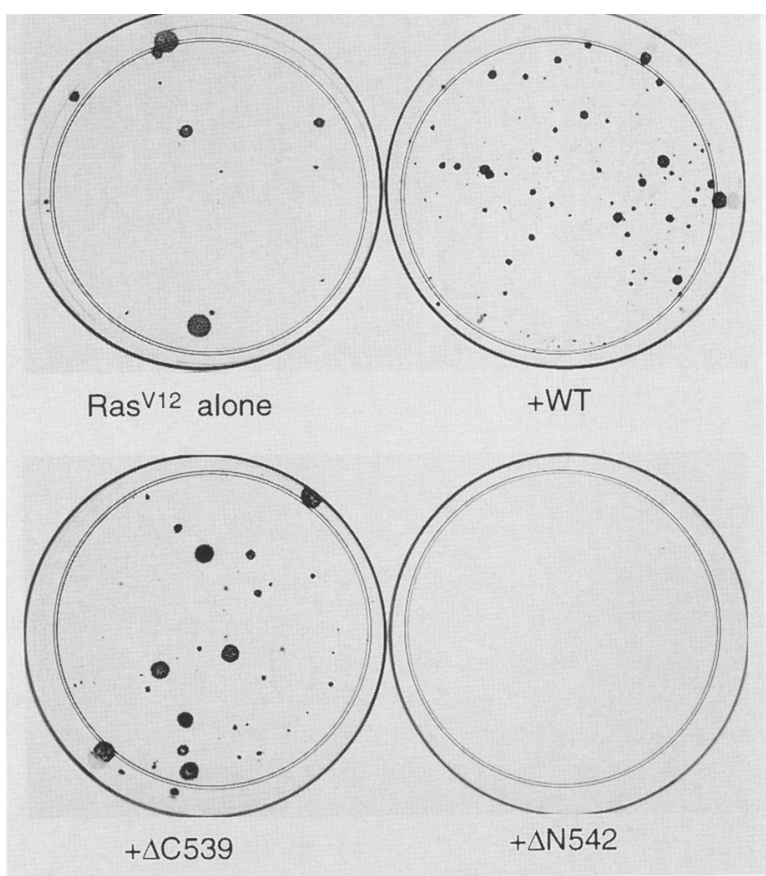

Figure 2. Effect of mKSRl on Ha-Ras ${ }^{\mathrm{V} 12}$-mediated cell transformation. Induction of focus formation in Balb/3T3 cells by the expression of $\mathrm{Ha}-\mathrm{Ras}^{\mathrm{V} 12}$ alone or by the coexpression of Ha-Ras ${ }^{\mathrm{V} 12}$ with either WT, $\Delta \mathrm{C} 539$ or $\Delta \mathrm{N} 542$. Two additional transfection experiments with different DNA preparations produced the similar results as the one shown. The average number of foci for $\mathrm{Ha}-\mathrm{Ras}^{\mathrm{V} 12}$ alone was 14, 105 for $\mathrm{Ha}-\mathrm{Ras}^{\mathrm{V} 12}+\mathrm{WT}, 34$ for Ha-Ras ${ }^{\mathrm{V} 12}+\Delta \mathrm{C} 539$, and 0 for Ha-Ras ${ }^{\mathrm{V} 12}+\Delta \mathrm{N} 542$. 
on oocyte maturation induced by other activators of the MAPK cascade. WT and $\Delta \mathrm{N} 542$ were coexpressed in oocytes with either Tpr-Met, an activated version of the hepatocyte growth factor receptor that functions upstream of Ras (Daar et al. 1991), or $\Delta$ NRaf, an aminoterminal-truncated Raf-1 protein that is activated in a Ras-independent manner (Fabian et al. 1993). As with Ha-Ras ${ }^{\mathrm{V} 12}$, Tpr-Met-induced maturation was augmented by the expression of WT mKSR1 (Fig. 3A) and blocked by the expression of $\Delta$ N542 (Fig. 3A). In contrast, oocyte maturation induced by $\Delta N R$ af was neither enhanced by WT nor was it blocked by $\Delta$ N542 (Fig. 3A). However, in oocytes coexpressing $\Delta \mathrm{NR}$ af and $\Delta \mathrm{N} 542$, the percentage of oocytes undergoing GVBD was reduced (Fig. 3A) and the time required for meiotic maturation was prolonged

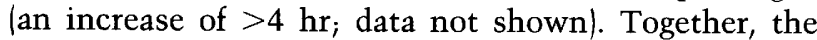
findings that WT alone could not induce oocyte maturation and that it only affected the rate of Ras-dependent GVBD indicate that mKSRl function is regulated by Ras.

\section{A functional kinase domain is required for the dominant-inhibitory activity of $\Delta N 542$}

To investigate whether the catalytic activity of $\Delta \mathrm{N} 542$ is required for its dominant-inhibitory activity, we generated mutant $\Delta \mathrm{N} 542$ proteins that contained alterations in two sequences that have been shown to be required for the catalytic activity of other kinases. Unlike Drosophila KSR and most other kinases that contain a lysine residue in kinase subdomain II (Hanks et al. 1988), mKSR 1 contains an arginine residue. Therefore, the arginine at amino acid position 589 was mutated either to a lysine residue $\left(\Delta N 542^{R>K}\right)$, which should retain catalytic activity, or to a methionine residue $\left(\Delta \mathrm{N} 542^{\mathrm{R}>\mathrm{M}}\right)$, which should abolish catalytic activity. In addition, the aspartic acid residue in the conserved DFG motif (Hanks et al. $1988)$ was mutated to a valine residue $\left(\Delta N 542^{\text {DFG }>V F G}\right)$. As a control, kinase-defective Raf-1 (KD-Raf), which has been shown previously to block Ha-Ras ${ }^{\mathrm{V} 12}$-induced GVBD (Fabian et al. 1993) was also examined. When expressed in oocytes, $\Delta \mathrm{N} 542^{\mathrm{R}>\mathrm{K}}$ efficiently blocked Ha$\mathrm{Ras}^{\mathrm{V} 12}$-induced maturation, whereas $\Delta \mathrm{N} 542^{\mathrm{R}>\mathrm{M}}$ and $\Delta \mathrm{N} 542^{\mathrm{DFG}>\mathrm{VFG}}$ were unable to do so (Fig. 3B). Furthermore, in kinase assays using nonspecific substrates, $\Delta \mathrm{N} 542$, but not $\Delta \mathrm{N} 542^{\mathrm{R}>\mathrm{M}}$ demonstrated kinase activity (data not shown). Therefore, these findings suggest that the catalytic activity of $\Delta \mathrm{N} 542$ is required to block Ras-mediated signaling.

\section{Overexpression of Dm $\triangle N K S R$ in the Drosophila eye prevents photoreceptor cell differentiation}

To determine whether the dominant-negative behavior of the $\Delta \mathrm{N} 542$ kinase domain is unique to the mammalian mKSR1 protein, an amino-terminal truncated version of Drosophila melanogaster KSR (Dm $\triangle$ NKSR) was ectopically expressed in the Drosophila eye and examined for its effect on eye development. During Drosophila eye development, Ras 1 is required for photoreceptor cell differentiation (Simon et al. 1991). The best-studied example of this requirement is the differentiation of the R7 photoreceptor, which is controlled by the Sev RTK (for review, see Wassarman et al. 1995). Failure to activate the Ras1 pathway in the presumptive $\mathrm{R} 7$ cells prevents their differentiation as neurons and results in their development as non-neuronal cone cells. Con-
A

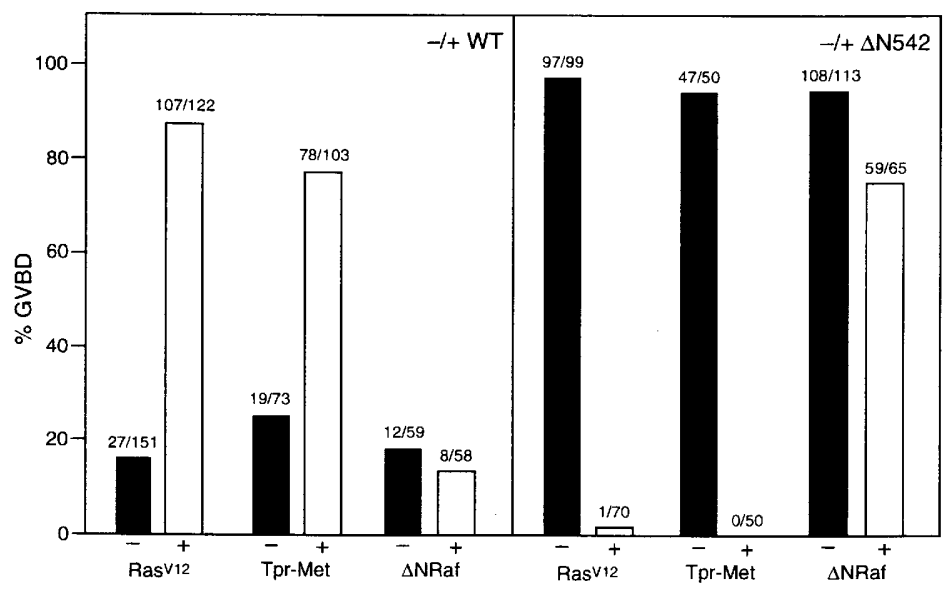

B

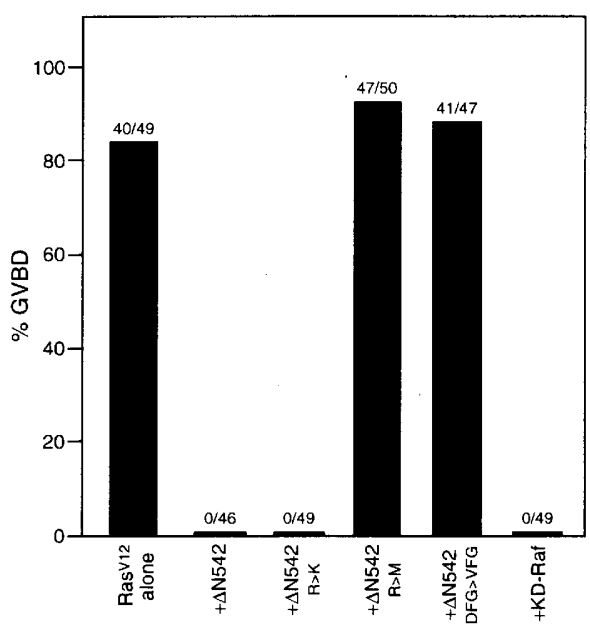

Figure 3. The isolated mKSR1 kinase domain requires an intact catalytic domain to block Ras-dependent signaling. $(A)$ Induction of Xenopus oocytes meiotic maturation by the coexpression of WT or $\Delta$ N542 mKSR1 with either Ha-Ras ${ }^{\mathrm{V} 2}$, Tpr-Met, or $\Delta$ NRaf. Buffer $(-)$ or RNA (30 ng) encoding WT or $\Delta \mathrm{N} 542$ (+) was injected into defolliculated stage VI oocytes. After 8-12 hr oocytes were injected with either Ha-Ras ${ }^{\mathrm{V} 12}$, Tpr-Met, or $\Delta$ NRaf RNA. Oocytes were scored for GVBD $\sim 5-10 \mathrm{hr}$ after the second injection. $(B)$ Induction of meiotic maturation by the coexpression of $\mathrm{Ha}-\mathrm{Ras}^{\mathrm{V} 12}$ with either $\Delta \mathrm{N} 542, \Delta \mathrm{N} 542^{\mathrm{R}>\mathrm{K}}, \Delta \mathrm{N} 542^{\mathrm{R}>\mathrm{M}}, \Delta \mathrm{N} 542^{\mathrm{DFG}>\mathrm{VFG}}$, or KD-Raf. Oocytes were injected as described in Fig. $1 \mathrm{~B}$ and scored for GVBD $\sim 15-20 \mathrm{hr}$ after the second injection. The numbers obtained represent a compilation of two independent experiments where equivalent amounts of the KSR mutant and Ha-Ras ${ }^{\mathrm{V} 12}$ proteins were expressed. 
versely, ectopic activation of the Rasl pathway transforms cone cells into R7 cells.

Using a strategy previously used to generate a truncated version of Drosophila Raf (DRaf) (Dickson et al. 1992), sequences corresponding to the Dm KSR kinase domain (amino acids 484-966) were introduced downstream of the first 455 amino acids of Tor ${ }^{4021}$, which includes the Torso extracellular and transmembrane domains. The tor ${ }^{4021} \Delta N k s r$ sequences were then inserted into the $s E$ P-element vector that directs specific transgene expression in the Drosophila eye (Dickson et al. 1992). By P-element-mediated germ-line transformation, five independent transgenic fly lines containing the $s E$ tor $^{4021} \Delta \mathrm{Nksr}$ construct were obtained. All five lines displayed a similar rough-eye phenotype (Fig. 4B), and inspection of tangential eye sections revealed that the tor $^{4021} \Delta \mathrm{Nksr}$ transgene had prevented $\mathrm{R} 7 \mathrm{cell}$ differentiation (Fig. 4E). This inhibitory effect was not restricted to the R7 cells but also affected the differentiation of outer photoreceptors because the transgene was expressed in a subset of these cells as well (Bowtell et al.

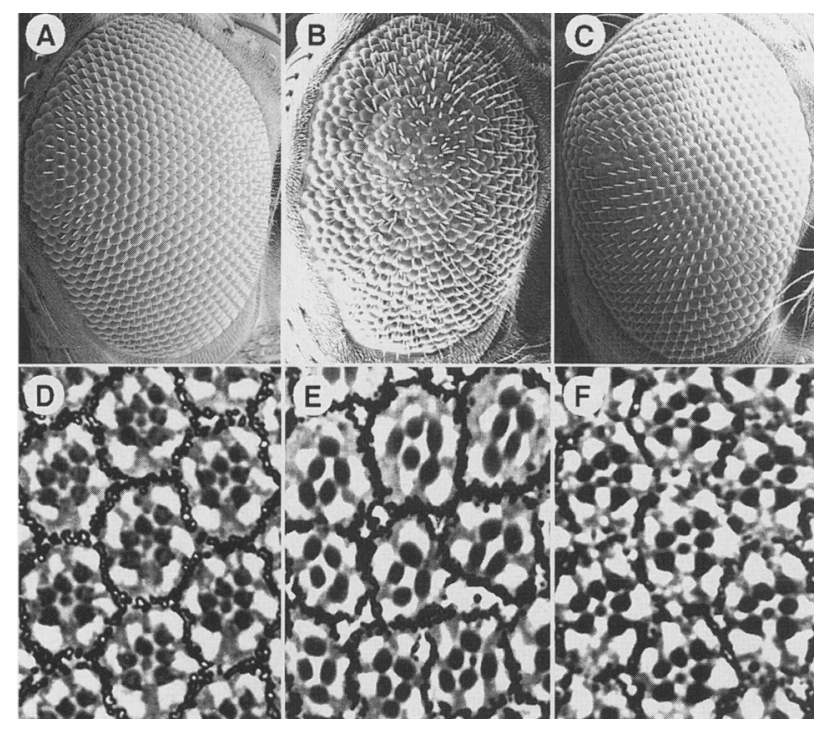

Figure 4. Dm $\triangle$ NKSR kinase domain blocks Drosophila photoreceptor cell differentiation. Scanning electron micrographs and apical tangential sections, respectively, of adult Drosophila eyes of the following genotypes: wild type $(A, D) ; \mathrm{P} \mid s E$ tor $\left.^{4021} \Delta N k s r\right] /+(B, E) ; \mathrm{P}\left[s E-\right.$ tor $\left.^{4021} \Delta N k s r^{K>M}\right] /+(C, F)$. Anterior is to the right. The apical tangential section of an adult wild-type eye $(D)$ reveals the characteristic trapezoidal arrangement of the rhabdomeres (the light-sensing organelles that appear as dark dots) in each ommatidium, which corresponds to the position of the photoreceptors. The six rhabdomeres that occupy the periphery of the trapezoid correspond to the position of the outer photoreceptors (R1-R6), whereas the smaller central rhabdomere corresponds to the position of the $\mathrm{R} 7$ photoreceptor. The extent of photoreceptor ablation caused by the $\mathrm{P}[s E$ tor $^{4021} \Delta \mathrm{Nksr}$ ] construct was evaluated by counting the number of photoreceptors per ommatidium in several apical sections similar to the one shown in $(E)$. Of 815 ommatidia analysed, at least $80 \%$ were missing an $\mathrm{R} 7$ cell, $65 \%$ were missing one outer cell (R1-R6) and $29 \%$ were missing more than one outer cell.
1991|. To determine whether the catalytic activity of Dm $\triangle$ NKSR is required for this phenotype, we generated a kinase defective molecule by mutating the lysine codon at position 705 to a methionine residue. Four independent transgenic lines were derived using the $\mathrm{P}\left[\right.$ tor $\left.^{4021} \Delta N k s r^{K>M}\right]$ construct, and in all four cases the eye was essentially wild type (Fig. 4C,F), indicating that the catalytic function of Dm $\triangle N K S R$ is required for the impairment of photoreceptor cell differentiation. Because photoreceptor cell differentiation is controlled by Ras1, Dm $\triangle$ NKSR presumably exerts its effect by interfering with Rasl-dependent signal transduction. The observation that the $t^{2}{ }^{4021} \Delta N k s r$ transgene strongly suppressed the extra R7 cell phenotype caused by overexpression of Ras $1^{V 12}$ in cone cells (data not shown) provides further support for this model. Therefore, these findings are consistent with the behavior of $\Delta \mathrm{N} 542$ and indicate that the isolated Dm KSR kinase domain also acts in a dominant-inhibitory manner.

Effect of mKSR1 on the endogenous MAPK pathway in Xenopus oocytes

To address the mechanism by which mKSR1 alters Rasmediated signal transduction, we examined the effect of the mKSR 1 proteins on the endogenous MAPK pathway in Xenopus oocytes. For these experiments, oocytes expressing $\mathrm{Ha}-\mathrm{Ras}{ }^{\mathrm{V} 12}$ alone or coexpressing $\mathrm{Ha}-\mathrm{Ras}^{\mathrm{V} 12}$ with either WT, $\Delta C 539$, or $\Delta$ N542 were lysed 3 and $11 \mathrm{hr}$ after Ras injection, and the activities of the endogenous Raf-1, MEK1, and MAPK were evaluated (Fig. 5B,C). At 3 hr (prior to the induction of GVBD), the activities of Raf-1, MEK1, and MAPK were all elevated in oocytes expressing Ha-Ras ${ }^{\mathrm{v} 12}$ alone. However, a reproducible 1.4-fold increase in MAPK activity was seen in oocytes coexpressing $\Delta \mathrm{C} 539$ and $\mathrm{Ha}-\mathrm{Ras}^{\mathrm{V} 12}$ and a greater than twofold enhancement of MEKI and MAPK activities was seen in oocytes coexpressing WT and Ha-Ras ${ }^{\mathrm{v} 12}$. Further, in oocytes coexpressing WT and Ha-Ras ${ }^{\mathrm{V} 12}$, the MAPK activity had already reached its maximal level by $3 \mathrm{hr}$. At $11 \mathrm{hr}$ (when GVBD was complete), Raf-1, MEK1, and MAPK activities were further elevated in oocytes expressing Ha-Ras ${ }^{\mathrm{v} 12}$ alone, although no significant enhancement was observed in oocytes coexpressing WT or $\Delta \mathrm{C} 539$ and Ha-Ras. These findings indicate that the net effect of WT mKSR1 was an acceleration of MEK and MAPK activation. Interestingly, at both time points, Raf-1 activity was elevated three- to fourfold in oocytes coexpressing $\triangle N 542$, but MEK1 and MAPK were not activated nor did MAPK become tyrosine phosphorylated (Fig.5B). The enhancement of Raf-1 activity in oocytes coexpressing $\Delta$ N542 was not attributable to direct phosphorylation and activation of Raf-1 by the isolated mKSR1 kinase domain, because the catalytically inactive $\Delta \mathrm{N} 542^{\mathrm{R}>\mathrm{M}}$ also enhanced Raf-l activity in the presence of Ha-Ras ${ }^{\mathrm{V} 12}$ (Fig. $5 \mathrm{C}$ ). However, in contrast to $\Delta \mathrm{N} 542, \Delta \mathrm{N} 542^{\mathrm{R}>\mathrm{M}}$ did not inhibit the activation of MEK1 or MAPK by Ha-Ras ${ }^{\text {v12 }}$ (Fig. 5 C). In addition, expression of either WT or $\triangle \mathrm{N} 542$ alone in oocytes had no effect on the activities of Raf-1, MEK1, and MAPK (Fig. 
A

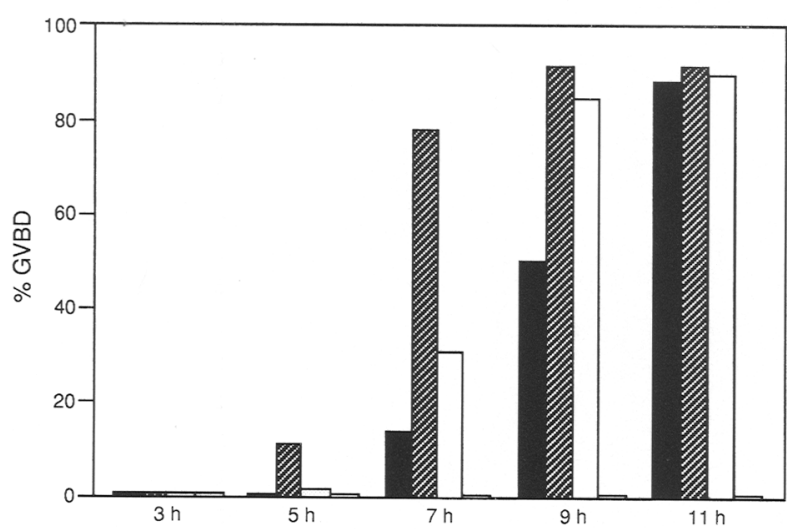

B
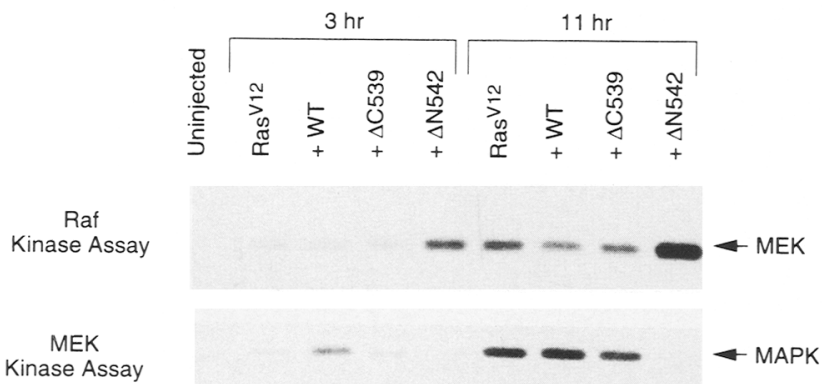

MAPK

Kinase Assay

$\alpha$ P-Tyr Blot
C

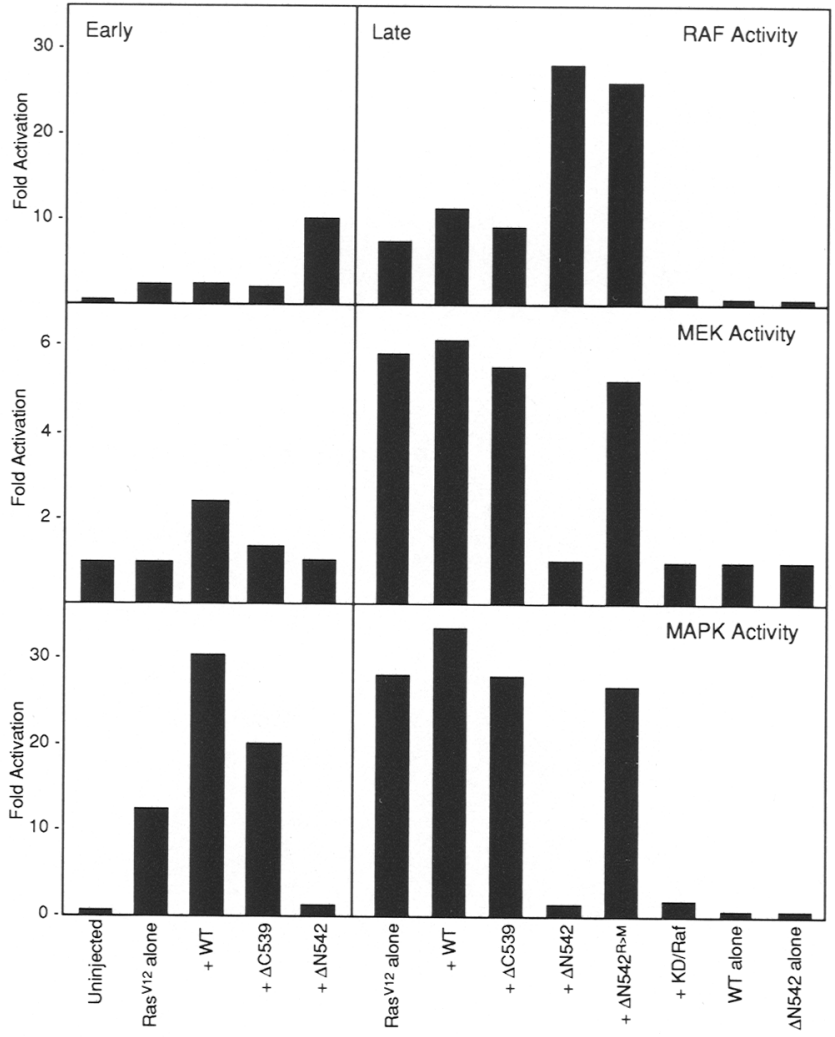

Figure 5. Effect of mKSR1 on Raf-1, MEK 1 and MAPK activities in Xenopus oocytes. $(A)$ Kinetics of GVBD induced by the expression of Ha-Ras ${ }^{\mathrm{V} 12}$ alone (solid bars) or by the coexpression of Ha-Ras ${ }^{\mathrm{V} 12}$ with either WT (hatched bars), $\Delta \mathrm{C} 539$ (open bars), or $\Delta \mathrm{N} 542$ (shaded bars). Xenopus oocytes were injected as described in Fig. 1B and GVBD was scored (expressed in percentage) at the indicated time. The result of one representative experiment is shown. $(B)$ Xenopus oocytes expressing Ha-Ras ${ }^{\mathrm{V} 12}$ alone or coexpressing Ha-Ras ${ }^{\mathrm{V} 12}$ with either WT, $\Delta \mathrm{C} 539$ or $\Delta \mathrm{N} 542$ were collected 3 or $11 \mathrm{hr}$ after the second injection (Ha-Ras ${ }^{\mathrm{V} 12} \mathrm{RNA}$ ). In vitro protein kinase assays were performed as described in Materials and Methods. The position of MEK1, MAPK, or MBP, used as exogenous substrates in these assays, is indicated by an arrow. Tyrosine-phosphorylated (activated) MAPK was detected by analyzing $\alpha$ MAPK immunoprecipitates with a phosphotyrosine antibody $(\alpha \mathrm{P}-\mathrm{Tyr})$. Lysates were equalized for protein expression by immunoblot analysis. (C) Xenopus oocytes expressing Ha-Ras ${ }^{\mathrm{V} 12}$, KD-Raf, WT or $\Delta \mathrm{N} 542$ alone or coexpressing Ha-Ras ${ }^{\mathrm{V} 12}$ with either WT, $\Delta \mathrm{C} 539, \Delta \mathrm{N} 542$, or $\Delta \mathrm{N} 542^{\mathrm{R}>\mathrm{M}}$ were collected at early $(3-5 \mathrm{hr}$ after the second injection) and late time points $(\sim 10-15 \mathrm{hr}$ after the second injection). Raf-1, MEK1, and MAPK activities were determined as described in $B$ using MEK1, MAPK, and MBP (respectively) as substrates. The amount of ${ }^{32} \mathbf{P}$ incorporated into each substrate was determined. The activity of uninjected oocytes was expressed as one and the fold activation for each sample type represents an average of at least three experiments.

5C). These findings suggest that $\Delta \mathrm{N} 542$ blocks Ras-mediated signaling by interfering with MEK1 and MAPK activation and that it indirectly enhances Raf- 1 activity. Furthermore, the catalytic function of $\Delta \mathrm{N} 542$ was required for the block in MEK1 and MAPK activation but was not needed for the enhancement in Raf-l activity.

WT and $\Delta N 542$ associate with Raf-1 in a Ras-dependent manner

To understand how $\Delta$ N542 influences Raf-1 activity, we performed transfection experiments in 293 cells. The cells were transiently transfected with DNAs encoding Ha-Ras ${ }^{\mathrm{v} 2}$, Raf-1, and either WT, $\Delta \mathrm{C} 539$, or $\Delta \mathrm{N} 542$. After $48 \mathrm{hr}$, the cells were lysed and Raf-1 immunoprecipitates were prepared and examined for the presence of mKSR1. By immunoblot analysis, WT and $\Delta$ N542 were found to coimmunoprecipitate with Raf-1, whereas $\Delta$ C539 did not, even though it was well expressed in the 293 cells (Fig. 6A). To confirm these findings, we immunoprecipitated mKSR1 from transfected 293 cells and found that the interaction between $\Delta N 542$ and Raf-1 re- 
Thierren et al.

A

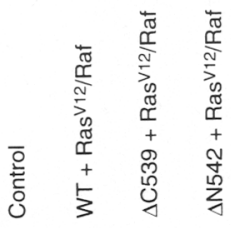
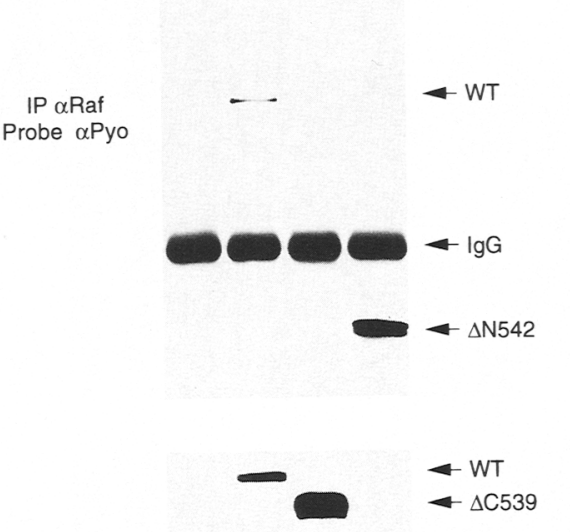

C

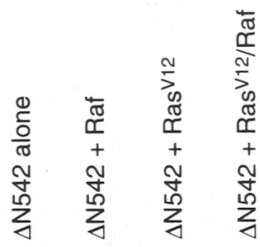

Probe $\alpha$ Raf $\quad \longrightarrow$ Raf

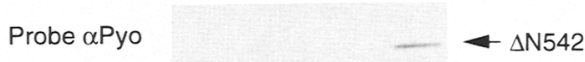

Probe $\alpha$ Ras $\quad 2 \div$ Ras $v 12$

Membrane Fraction

Lysate Probe $\alpha$ Pyo

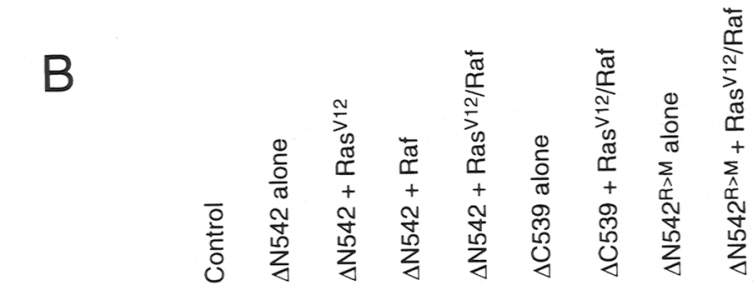
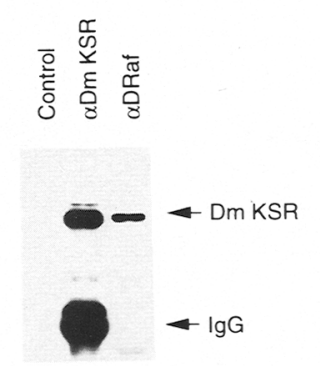

Probe $\alpha \mathrm{Dm}$ KSR

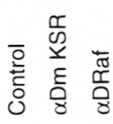

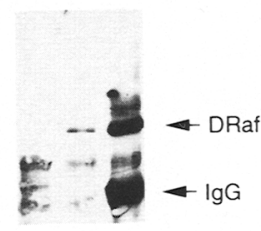

Probe $\alpha$ DRaf

IP $\alpha$ Pyo

Probe $\alpha$ Raf

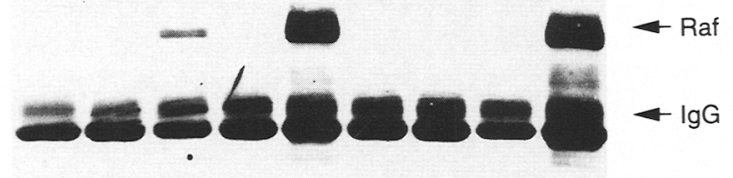
$\lg G$

Figure 6. mKSRl and Raf- 1 interact in vivo in a Ras-dependent manner. $(A) 293$ cells coexpressing Ha-Ras ${ }^{\mathrm{v} 12}$, Raf-1, and either WT, $\Delta \mathrm{C} 539$, or $\Delta \mathrm{N} 542$ were lysed in NP-40 buffer and the Raf-1 proteins were immunoprecipitated (IP) using a Raf-1 antibody ( $\alpha$ Raf). Immunoprecipitates were resolved by $10 \%$ SDS-PAGE and examined by immunoblotting using a polyoma epitope tag antibody ( $\alpha$ Pyo) to detect Pyo-tagged mKSRl (top). Total lysates (bottom) were analyzed by immunoblotting using $\alpha$ Pyo to evaluate the expression level of mKSRl. The position of the mKSRl proteins and the immunoglobulin heavy chain (IgG) are indicated by arrows. The control lysate was prepared from mock-transfected 293 cells. $(B) 293$ cells expressing $\Delta$ N542 or $\Delta$ C539 alone or coexpressing Ha-Ras ${ }^{\mathrm{V} 12}$ and/or Raf-1 were lysed and immunoprecipitated (IP) using $\alpha$ Pyo. Immunoprecipitates were analyzed by immunoblotting with $\alpha$ Raf- 1 antibody. The positions of Raf-1 and IgG are indicated by arrows. (C) Membrane fractions were isolated from 293 cells expressing $\Delta N 542$ alone or coexpressing $\Delta \mathrm{N} 542$ with $\mathrm{Ha}-\mathrm{Ras}^{\mathrm{v} 12}$ and/or Raf-1 and analyzed by immunoblotting with either $\alpha$ Raf- $1, \alpha$ Pyo, or $\alpha$ Ras. $(D)$ Lysates prepared from wild-type Drosophila embryos were immunoprecipitated with either mock antibody supernatant (Control), $\alpha \mathrm{Dm}$ KSR or $\alpha \mathrm{DRaf}$. The immunoprecipitates were analyzed by immunoblotting with $\alpha \mathrm{Dm}$ KSR (left) or $\alpha \mathrm{DRaf}$ (right). The positions of endogenous Dm KSR, DRaf and IgG are indicated by arrows.

quired the presence of Ha-Ras ${ }^{\mathrm{V} 12}$ and that the catalytically inactive $\Delta N 542^{R>M}$ also associated with Raf-1 (Fig. $6 \mathrm{~B})$. In addition, the endogenous Raf- 1 protein was de- tected in $\Delta$ N542 immunoprecipitates from cells transfected with Ha-Ras ${ }^{\mathrm{V} 12}$ and $\Delta \mathrm{N} 542$ (Fig. 6B). By coimmunoprecipitation experiments, mKSRl was not found to 
directly interact with Ha-Ras ${ }^{\mathrm{V} 12}$ (data not shown). However, when transfected 293 cells were fractionated into membrane and cytosol fractions, $\Delta \mathrm{N} 542$ was detected in the membrane fraction of cells transfected with HaRas $^{\mathrm{V} 12}$ and Raf-1 (Fig. 6C), suggesting that $\Delta \mathrm{N} 542$ is a component of a membrane-bound signaling complex.

To determine whether the interaction between mKSRl and Raf- 1 could be detected under conditions where the KSR proteins were not being overexpressed, we performed coimmunoprecipitation experiments using Drosophila embryo extracts. For these studies, the Drosophila extracts were immunoprecipitated using antibodies to Dm KSR or DRaf and then examined for the presence of either Dm KSR or DRaf. Immunoblot analysis revealed that the endogenous Dm KSR migrated as a single band with a molecular mass of $\sim 120 \mathrm{kD}$ and was present in the DRaf immunoprecipitates (Fig. 6D, left panel). Furthermore, the $85-\mathrm{kD}$ DRaf protein was found in Dm KSR immunoprecipitates (Fig. 6D, right panel). These results indicate the association between Dm KSR and DRaf does occur in Drosophila embryos.

\section{Discussion}

KSR is a novel component of Ras-mediated signaling pathways that was recently indentified in genetic screens for downstream effectors of Ras in Drosophila and C. elegans (Therrien et al. 1995; Kornfeld et al. 1995; Sundaram and Han 1995). At the conclusion of these genetic studies, the precise role of KSR in signal transduction had not been elucidated and the following questions were left unanswered: (1) Is the activity of KSR Ras-dependent? (2) Is KSR a kinase that activates Raf-1? and (3) Is KSR a Raf-like molecule functioning in a pathway parallel to the Raf-1/MEK1/MAPK pathway? In this report, we show that the activity of KSR is indeed Rasdependent; however, the function of KSR is more complex than originally anticipated. We find that whereas KSR does interact with Raf-1, it is not a Raf-1 kinase /Fig. 5 and data not shown), but rather is an integral component of a membrane-bound kinase signaling complex that forms in response to Ras activation and facilitates signal transmission within the MAPK module (Fig. 7A). KSR also does not appear to function as a Raf-like molecule. In fact, in sharp contrast to the biological activity of the isolated domains of Raf-1 (Daum et al. 1994), the mKSR1 amino-terminus retains some of the cooperativity with Ras, whereas the kinase domain blocks Ras signaling as well as MEKl and MAPK activation (Fig. 7B). Although we have not yet identified the physiological substrate of KSR, we do find that KSR augments the biological activity of Ras and accelerates MEK and MAPK activation (Fig. 7A). Based on our studies, we propose that the activity of KSR may be involved in mediating protein interactions that facilitate the activation of the MAPK cascade rather than in directly regulating these kinases by phosphorylation events. Together, our findings indicate that KSR is an integral component of the Ras/Raf-1/MEK1/MAPK cascade functioning via a
A

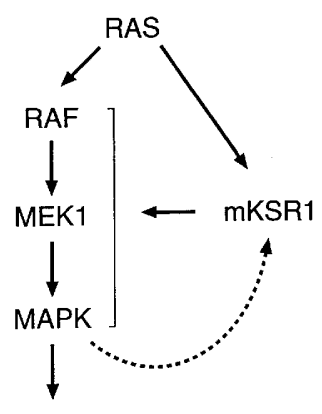

B

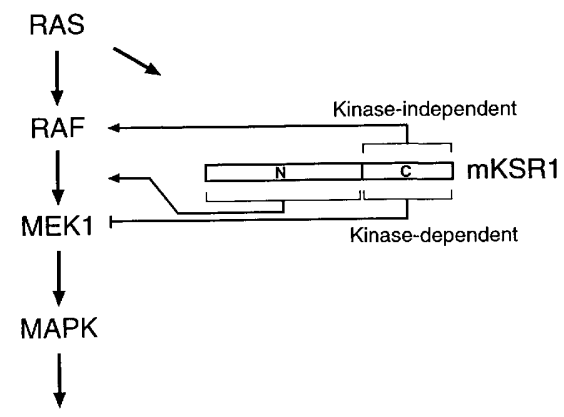

Figure 7. Model summarizing the Ras-dependent effects of the mKSR1 on the components of the MAPK module. $|A|$ mKSRl facilitates Ras-dependent signal propagation within the MAPK cascade. The arrow pointing to a bracket comprising the MAPK module indicates that the exact step where mKSRl acts is still unclear. The dashed arrow indicates that the activity of mKSRl (which contains three MAPK consensus phosphorylation sites in its amino-terminal domain) may be regulated by activated MAPK. $(B)$ Effects of the isolated amino- and carboxy-terminal domains of $\mathrm{mKSRl}$ are indicated by an arrow (positive effect) or a blunted line (negative effect). See text for details.

novel mechanism to modulate signal propagation within the MAPK module.

\section{A role for KSR in Ras-mediated signaling}

In our studies, we find that mKSR1 facilitates Ras-mediated signal transduction. In two independent biological assays, Xenopus oocyte maturation and fibroblast cell transformation, mKSRl expression enhanced the effects of activated Ras. mKSR1 also cooperated with Tpr-Met to induce oocyte maturation but had no effect on activated Raf-induced maturation, indicating that the function of mKSR1 is itself Ras-dependent (Fig. 3A). The effect of mKSRl on Ras-mediated signal transduction appears to be attributable to an accelerated activation of MEK1 and MAPK (Fig. 5). Because Xenopus oocyte maturation depends on the activation of the MAPK pathway, this acceleration probably accounts in part for the ability of mKSR1 to cooperate with Ha-Ras ${ }^{\mathrm{V} 12}$ to induce GVBD. The effect of mKSRl on MEKl and MAPK does not appear to be caused by direct phosphorylation and activa- 
tion of these kinases, because all of our attempts to identify these proteins as physiological substrates of $\mathrm{mKSR} 1$ have failed, or caused by an enhancement in Raf- 1 activity because no change in Raf-1 activity was detected. Nonetheless, although the exact mechanism by which mKSR1 accelerates MEK1 and MAPK activation is unknown, the finding that mKSR 1 associates with Raf- 1 in a Ras-dependent manner suggests that $\mathrm{mKSR} 1$ is a integral component of the Raf-1/MEK1/MAPK pathway.

\section{Functional differences between mKSR1 and Raf-1}

By sequence analysis, mKSR 1 is most closely related to the Raf family of serine/threonine kinases. However, our studies have revealed striking functional differences between mKSR1 and Raf-1. Expression of the Raf-1 aminoterminal domain has been shown previously to block the transmission of Ras-dependent signals, whereas expression of the Raf- 1 kinase domain has been found to mimic many of the effects of activated Ras, including the constitutive activation of MEK1 (Daum et al. 1994). In contrast to Raf-1, the isolated amino-terminal domain of mKSR 1 facilitates Ras-mediated signal transduction, whereas the isolated mKSR1 kinase domain prevents Ras signaling. These differences between mKSRl and Raf mutants strongly suggest that mKSR 1 does not function as a Raf-like molecule but, rather, acts in a novel manner to affect signal propagation within the MAPK cascade.

In our studies, the isolated mKSR1 amino-terminal domain $(\triangle \mathrm{C} 539)$ was capable of cooperating with activated Ras to promote oocyte maturation (Figs. 1B and 5A) and cell transformation (Fig. 2). However, the effect of $\Delta$ C539 on Ras signaling was less than that observed for WT, demonstrating that the kinase domain of mKSRl is required for maximal activity. The reduced cooperativity of the amino-terminal domain appears to be caused by a weaker acceleration in the activation process of MEKI and MAPK. In fact, we were only able to reproducibly detect an increase in MAPK activity (Figs. 5B,C). The mechanism by which the mKSRl amino-terminal domain mediates this effect is unknown. However, an important clue by which to elucidate this phenomenon may lie in the observation that a region including the cysteine-rich motif of mKSR 1 appears to be required for the cooperative effect (Fig. 1B). In other proteins, such as protein kinase $\mathrm{C}$ and Raf-1, cysteine-rich domains have been found to mediate protein interactions and the binding of activating ligands (Berg 1986; Parker et al. 1986; Michaud et al. 1995). Therefore, to understand the cooperative function of mKSR1, experiments are currently under way to identify potential molecules that associate with the cysteine-rich CA3 domain.

Unexpectedly, our studies revealed that the carboxyterminal kinase domain of KSR efficiently blocked Rasmediated signaling and prevented Xenopus oocyte maturation, cellular transformation, and Drosophila eye development. The dominant-negative behavior of the mKSR1 kinase domain is surprising because in the context of the full-length KSR molecule, the kinase domain functions in a positive manner (Fig. 5). By measuring the activity of components of the MAPK cascade, we found that expression of $\triangle \mathrm{N} 542$ alone did not affect the basal activity of Raf-1, MEK1, or MAPK. However, when $\triangle$ N542 was coexpressed with activated Ras, endogenous Raf- 1 activity was stimulated, and MEK1, and MAPK failed to become activated. Intriguingly, the catalytic function of $\Delta \mathrm{N} 542$ was required for the block in MEK1 and MAPK activation but was not needed for the enhancement of Raf- 1 activity, indicating that these opposing effects represent different functional aspects of mKSR1 (Fig. 7B). Because MEK1 is the physiological substrate of Raf-1, $\Delta$ N542 appears to be blocking Raf-1 activation of MEK1. One explanation that could account for this phenomenon is that $\Delta \mathrm{N} 542$ might activate a phosphatase that specifically deactivates MEK1, resulting in the apparent inability of Raf- 1 to mediate MEKl activation. Alternatively, $\triangle N 542$ might physically prevent the access of Raf-1 to MEK1. A Ras/Raf-1/MEK1 complex has been shown to form prior to MEK1 activation (Moodie et al. 1993). Therefore, in this scenario, the isolated mKSR1 kinase domain ( $\Delta$ N542) might constitutively phosphorylate a target that interferes with the localization of MEK1 to the Ras/Raf-1 complex.

Although $\triangle$ N542 blocks meiotic maturation induced by activated Ras, it does not prevent activated Raf-induced GVBD (Fig. 3A), suggesting that $\triangle \mathrm{N} 542$ acts upstream of Raf-1. However, these observations would be consistent with $\Delta \mathrm{N} 542$ inhibiting a step between Raf-1 and MEKl activation, if high overexpression of activated Raf- 1 could overwhelm the block of $\Delta \mathrm{N} 542$. In this case, the activation of MEK1 and MAPK would be delayed but as the protein level of activated Raf-1 accumulated, it would eventually override the block of $\Delta$ N542 and activate MEK1. Our data suggest that this may indeed be the case because the presence of $\Delta \mathrm{N} 542$ greatly delayed the kinetics of Raf-induced oocyte maturation.

\section{mKSR1 and Raf-1 form a Ras-dependent complex}

Through coimmunoprecipitation experiments, we have found that $\mathrm{mKSR} 1$ and Raf- 1 interact in a Ras-dependent manner. The association of KSR and Raf was also observed in Drosophila embryo extracts where neither of the proteins was overexpressed, indicating that this interaction occurs in vivo and is biologically relevant. The findings that mKSR 1 and Raf- 1 associate in a Ras-dependent manner and that the complex is found at the membrane provide strong evidence that these two kinases have a close functional relationship (Fig. 6). However, neither mKSR1 nor Raf- 1 appears to be a substrate of the other (data not shown). The dependency on Ras further indicates that the association between mKSR1 and Raf- 1 is regulated. One consequence of this interaction might involve structural changes that alter the activity of either of the two kinases. The idea that the MKSR1/ Raf-1 interaction modulates kinase function is supported by the findings that $\Delta \mathrm{N} 542$ not only associates with Raf-1 but also stimulates its enzymatic activity in vivo, even when the catalytic function of $\Delta \mathrm{N} 542$ is elim- 
inated by mutation. We speculate that $\Delta \mathrm{N} 542$ could be mediating this effect by stabilizing the active conformation of Raf-1, by increasing the interaction of Raf- 1 with an activator molecule, or by blocking a negative feedback loop that would serve to down modulate Raf-l activity. Experiments are currently under way to test these models.

\section{A speculative model for KSR function}

Although several models can be envisioned to explain our findings, one model, which accounts for the behavior of both the mKSR 1 amino-terminal and carboxy-terminal domains, is that mKSR 1 may function to regulate the formation and subsequent disruption of a Raf-1/MEK1/ MAPK complex. The formation of such a complex would be required to avoid inappropriate signaling transmission attributable to promiscuous enzyme/substrate interactions. The occurrence of such complexes has been demonstrated in Saccharomyces cerevisiae, where the STE5 protein has been shown to function as a scaffolding molecule bridging the three kinases composing a MAPK module (Choi et al. 1994). By analogy, mKSRl alone or together with Raf-1 may form a complex that facilitates signal propagation among Raf-1, MEK1 and MAPK. Based on this model, the amino-terminal domain of mKSR1 would serve to stabilize a Raf-1/MEK1/MAPK complex and perhaps provide a docking site for additional molecules required for the activation of this module. In concert, activation of the kinase domain of mKSR 1 would generate the signal necessary for the disruption of the complex, thereby allowing MAPK to relocalize with its substrates. How the activity of mKSR1 is regulated is unknown, but an attractive possibility is that the signal activating the mKSR1 kinase domain may be provided by the newly activated MAPK itself (Fig. 7A). Evidence supporting this possibility comes from the observation that three consensus MAPK phosphorylation sites are located within the MKSRl amino-terminal domain and that this domain is an excellent substrate for MAPK in vitro (data not shown). In addition, we have detected a strong interaction between the amino-terminal domain of Dm KSR and Drosophila MAPK using a yeast two-hybrid interaction assay (data not shown). Therefore, once activated, MAPK could phosphorylate the amino-terminal domain of mKSR1, relieving its negative regulatory effect on the kinase domain. This step in turn would activate the catalytic function of the kinase domain, resulting in the disruption of the Raf-1/MEK1/ MAPK complex. If this model or a variation of it is valid, then separation of the amino- and carboxy-terminal domains would uncouple the normal regulation of mKSR 1 , thereby allowing the kinase domain to phosphorylate its target at an inappropriate time. Therefore, the dominantnegative effect of $\Delta$ N542 could be explained by the constitutive activity of the kinase domain disrupting or preventing the formation of the complex. To test this model, we are attempting to purify and to identify the components of the Ras/Raf/KSR complex. Among its constituents should be the physiological substrate of KSR.

\section{Materials and methods}

Plasmids

mKSR 1 deletion and point mutant constructs were generated by standard procedures (Sambrook et al. 1989) using a 4.1-kb fulllength mKSR 1 cDNA that was initially cloned into pBacPak-8 vector (Clontech). An oligonucleotide encoding two copies of a polyoma virus-derived (Pyo) epitope tag (amino acids MEYMPME; detected by a mouse mAb/ was inserted in frame, in a BssHII site, eight amino acids downstream of the initiation codon of the mKSR1 cDNA (the BssHII site was conserved at the 3 ' end of the Pyo epitope tag). The resulting construct was used as a template to make the various deletion and point mutant constructs described in this study. The $\Delta \mathrm{N} 90, \Delta \mathrm{N} 319$, $\Delta \mathrm{N} 397$, and $\Delta \mathrm{N} 542$ constructs were generated by deleting the Pyo-mKSR1 cDNA sequences between a HindIII, BamHI, EcoRV, or ApaI site, respectively, and the BssHII site at the 3' end of the Pyo epitope tag. The $\Delta \mathrm{C} 539, \Delta \mathrm{C} 424, \Delta \mathrm{C} 320$, and $\Delta C 249$ constructs were generated by deleting the sequences between an ApaI, BstXI, BamHI, or SmaI site, respectively, and the NotI site (from pBacPak-8 vector) located downstream of the mKSR 1 cDNA 3' untranslated region (UTR). An oligonucleotide containing a stop codon in three reading frames was inserted in a PacI site immediately downstream of the deleted sequences. $\Delta \mathrm{N} 542^{\mathrm{R}>\mathrm{K}}$ is the change of arginine 589 to a lysine residue in the $\Delta \mathrm{N} 542$ construct; $\Delta \mathrm{N} 542^{\mathrm{R}>\mathrm{M}}$ is the change of arginine 589 to a methionine residue; $\Delta N 542^{\mathrm{DFG}>\mathrm{VFG}}$ is the change of aspartic acid 700 to a valine residue. The mKSR1 cDNA derivatives described were transferred into the pSP64T transcription vector for expression in Xenopus oocytes and into the pcDNA3 vector (Invitrogen) for expression in mammalian cells. The Ha-Ras ${ }^{\mathrm{V} 12}$, Tpr-Met, $\triangle \mathrm{NRaf}$, and KD-Raf (kinase-defective) constructs were as described by Fabian et al. (1993).

The $s E$-tor ${ }^{4021} \Delta N k s r$ P-element construct was generated in three steps. First, a $3^{\prime}$-cDNA fragment of $D$. melanogaster ksr ( $\Delta N k s r)$ starting at amino acid 484 and ending at the UAG stop codon was amplified by PCR and inserted in frame immediately downstream of the first 455 amino acids of Tor ${ }^{4021}$ (Dickson et al. 1992). Second, an SV40-derived $\sim 800$-bp fragment containing a polyadenylation signal was inserted downstream of $\Delta N k s r$. Third, the chimeric tor ${ }^{4021} \Delta N k s r$ cDNA was inserted into a pW8 transformation construct derivative that contains the $s e v$ enhancer sequences followed by the $h s p 70$ promoter sequences (sE) (Dickson et al. 1992). The $s E-$ tor $^{4021} \Delta N k s r^{K>M}$ P-element construct was made like the previous construct, except that $k s r^{K>M}$ has the codon for lysine 705 changed to a methionine codon.

\section{Oocyte injection and analysis}

Oocytes were isolated and defolliculated as described previously (Fabian et al. 1993). Within $18 \mathrm{hr}$ of isolation, the oocytes were injected with $30 \mathrm{ng}$ of in vitro transcribed RNA encoding the various $\mathrm{mKSR} 1$ proteins. The oocytes were then injected 8-12 hr later with $30 \mathrm{ng}$ of either Ha-Ras ${ }^{\mathrm{vl} 2}, \Delta \mathrm{NRaf}$, or Tpr-Met RNA. Oocytes were scored for GVBD, as evidenced by the appearance of a white spot at the animal pole. This observation was verified by manual dissection of oocytes after fixation in $8 \%$ trichloroacetic acid. For biochemical analysis, oocytes were lysed $(10 \mu \mathrm{l}$ per oocyte) by trituration with a pipet tip in either Nonidet-40 (NP-40) buffer [ $20 \mathrm{~mm}$ Tris at $\mathrm{pH} 8.0,137 \mathrm{~mm} \mathrm{NaCl}$, $10 \%$ glycerol, $1 \%$ NP-40, 2 mM EDTA, aprotinin $(0.15 \mathrm{U} / \mathrm{ml}), 1$ 
mM phenylmethylsulfonyl fluoride (PMSF), $20 \mu \mathrm{M}$ leupeptin, 5 mM sodium vanadate) or RIPA buffer (20 mM tris at ph 8.0, 137 $\mathrm{mm} \mathrm{NaCl}, 10 \%$ glycerol, $1 \%$ NP- $40,0.5 \%$ sodium deoxycholate, $0.1 \%$ sodium dodecyl sulfate (SDS), 2 mM EDTA, aprotinin $(0.15 \mathrm{U} / \mathrm{ml}), 1 \mathrm{mM}$ PMSF, $20 \mu \mathrm{M}$ leupeptin, $5 \mathrm{mM}$ sodium vanadate). Lysates were cleared by centrifugation at $14,000 \mathrm{~g}$ for $5 \min$ at $4^{\circ} \mathrm{C}$.

\section{In vitro protein kinase assays}

Raf-1, MEK1, and MAPK activities were determined from the lysates of five oocytes. For Raf-1 and MAPK assays, the lysates were diluted with $700 \mu$ l of RIPA buffer and incubated for $4-6 \mathrm{hr}$ with either $3 \mu \mathrm{g}$ of Raf-l antibody (SC-133, Santa Cruz Biotechnology, Inc.) or $3 \mu \mathrm{g}$ of MAPK antibody (SC-154, Santa Cruz Biotechnology, Inc.). For MEK1 kinase assays, oocyte lysates were diluted with $700 \mu \mathrm{l}$ of NP-40 buffer and incubated with 5 $\mu \mathrm{g}$ of MEK1 antibody (Zymed). The antigen-antibody complexes were collected with protein A/G-agarose beads (Santa Cruz Biotechnology, Inc.). The immunoprecipitated proteins were washed three times with NP-40 buffer containing $1 \mathrm{~mm}$ sodium vanadate and once with $30 \mathrm{~mm}$ HEPES at $\mathrm{pH} 7.4$. The Raf- 1 complexes were then incubated in $40 \mu \mathrm{l}$ of kinase buffer containing $30 \mathrm{~mm}$ HEPES at $\mathrm{pH} 7.4,10 \mathrm{~mm} \mathrm{MnCl}_{2}, 5 \mathrm{~mm}$ $\mathrm{MgCl}_{2}, 1 \mathrm{mM}$ dithiothritol (DTT), $5 \mu \mathrm{M}$ ATP, $20 \mu \mathrm{Ci}$ of ${ }^{32} \mathrm{P} \mid \mathrm{ATP}$, and $0.5 \mu \mathrm{g}$ of kinase inactive MEK 1 (Dent et al. 1994); the MEK1 complexes in kinase buffer containing $30 \mathrm{mM}$ HEPES at $\mathrm{pH} 7.4,10 \mathrm{~mm} \mathrm{MnCl} 2,10 \mathrm{~mm} \mathrm{MgCl}, 1$ mM DTT, $5 \mu \mathrm{M} \mathrm{ATP,}$ $20 \mu \mathrm{Ci}$ of $\left[{ }^{32} \mathrm{P}\right] \mathrm{ATP}$, and $0.5 \mu \mathrm{g}$ of inactive MAPK (Upstate Biotechnology Inc.); and the MAPK complexes in kinase buffer containing $30 \mathrm{~mm}$ HEPES at $\mathrm{pH} 7.4,10 \mathrm{mM} \mathrm{MgCl}_{2}, 1 \mathrm{mM}$ DTT, $5 \mu \mathrm{M}$ ATP, $20 \mu \mathrm{Ci}$ of $\left[{ }^{32} \mathrm{P}\right] \mathrm{ATP}$, and $1 \mu \mathrm{g}$ of myelin basic protein (MBP) (Upstate Biotechnology, Inc.). After incubation for 20 min at $25^{\circ} \mathrm{C}$, the assays were terminated by the addition of gel loading buffer ( $4 \%$ SDS, $80 \mathrm{~mm}$ DTT, $10 \%$ glycerol). The samples were then resolved by SDS-polyacrylamide gel electrophoresis (SDS-PAGE) and the phosphoproteins were visualized by autoradiography.

\section{Cell transfection, coimmunoprecipitation assays, and membrane fractionation}

The plasmid DNAs $(5 \mu \mathrm{g})$ were transfected into 293 and Balb/ 3T3 cells by the calcium phosphate method (Wigler et al. 1978). $\mathrm{Balb} / 3 \mathrm{~T} 3$ cells were fixed and stained with $0.2 \%$ methylene blue 3 weeks after transfection, whereas 293 cells were lysed in NP-40 buffer $48 \mathrm{hr}$ after transfection. Cell lysates were equalized for protein expression by immunoblot analysis. Coimmunoprecipitation assays were performed by incubating lysates (from $5 \times 10^{7}$ cells) with the appropriate antibody for 4-6 hr at $4^{\circ} \mathrm{C}$. The antigen-antibody complexes were collected with protein A/G-agarose beads. The immunoprecipitates were then washed four times with cold NP-40 buffer before analysis by SDS-PAGE. Membrane preparations from the transfected 293 cells were isolated by hypotonic lysis followed by differential centrifugation as previously described (Stokoe et al. 1994).

\section{Drosophila manipulations}

Scanning electron microscopy and tangential sections of adult Drosophila eyes were performed as described by Kimmel et al. (1990) and Tomlinson and Ready (1987), respectively. P-element-mediated transformation of the germ-line was performed as described by Spradling and Rubin (1982). All crosses were performed at $25^{\circ} \mathrm{C}$.

Drosophila embryo extracts were prepared as described by
Sprenger et al. (1993) with a slight variation. Briefly, 0-18-hr embryos were dechorionated, resuspended $(0.1 \mathrm{~g} / \mathrm{ml})$ in ice-cold lysis buffer containing $20 \mathrm{~mm}$ Tris at $\mathrm{pH} 8.0 \mid, 137 \mathrm{~mm} \mathrm{NaCl}, 2$ mM EDTA, 1\% NP-40, $1 \mathrm{~mm}$ PMSF, $0.15 \mathrm{U} / \mathrm{ml}$ aprotinin, and $\mathrm{l}$ $\mathrm{mM}$ leupeptin, homogenized using a glass homogenizer (Wheaton; pestle A), and incubated on ice for $15 \mathrm{~min}$. Extracts were cleared by centrifugation at $4^{\circ} \mathrm{C}$ for $15 \mathrm{~min}$ at $12,000 \mathrm{~g}$. Coimmunoprecipitations were performed as described above using $1 \mathrm{ml}$ of embryo extract and antibodies recognizing either Dm KSR [a mouse mAb directed against a bacterially expressed protein corresponding to amino acids 128-258 of Dm KSR fused to glutathione $S$-transferase [GST)] or DRaf (a rabbit polyclonal antibody directed against amino acids 116-781 of DRaf).

\section{Acknowledgments}

We are grateful to M. Botchan, G.S. Martin, M. Simon, and members of the Morrison and Rubin laboratories for helpful discussion and critical reading of the manuscript. We thank $\mathrm{K}$. Mathes for excellent technical assistance, Bernard Ho for Drosophila embryo injections, and Lisa Megna for making the tor $^{4021} \Delta N k s r$ P-element construct. This work is supported in part by the National Cancer Institute of Canada and the Medical Research Council of Canada (M.T.), the Howard Hughes Medical Institute (G.M.R.), and the National Cancer Institute, Department of Health and Human Services, under contract with ABL (N.R.M. and D.K.M).

The publication costs of this article were defrayed in part by payment of page charges. This article must therefore be hereby marked "advertisement" in accordance with 18 USC section 1734 solely to indicate this fact.

\section{References}

Berg, J.M. 1986. Potential metal binding domains in nucleic acid binding proteins. Science 232: 485-487.

Birchmeier, C., D. Broek, and M. Wigler. 1985. Ras proteins can induce meiosis in Xenopus oocytes. Cell 43: 615-621.

Bowtell, D.D.L., T. Lila, W.M. Michael, D. Hackett, and G.M. Rubin. 1991. Analysis of the enhancer element that controls expression of sevenless in the developing Drosophila eye. Proc. Natl. Acad. Sci. 88: 6853-6857.

Choi, K.Y., B. Satterberg, D.M. Lyons, and E.A. Elion. 1994. Ste5 tethers multiple protein kinases in the MAP kinase cascade required for mating in S. cerevisiae. Cell 78: 499-512.

Cowley, S., H. Paterson, P. Kemp, and C.J. Marshall. 1994. Activation of MAP kinase kinase is necessary and sufficient for $\mathrm{PC} 12$ differentiation and for transformation of $\mathrm{NIH} 3 \mathrm{~T} 3$ cells. Cell 77: 841-852.

Daar, I.O., G.A. White, S.M. Schuh, D.K. Ferris, and G.F. Vande Woude. 1991. tpr-met oncogene product induces maturation-promoting factor activation in Xenopus oocytes. Mol. Cell. Biol. 11: 5985-5991.

Daum, G., I. Eisenmann-Tappe, H.W. Fries, J. Troppmair, and U.R. Rapp. 1994. The ins and outs of Raf kinases. Trends Biol. Sci. 19: 474-479.

Dent, P., Y.H. Chow, J. Wu, D.K. Morrison, R. Jove, and T.W. Sturgill. 1994. Expression, purification and characterization of recombinant mitogen-activated protein kinase kinases. Biochem. I. 303: 105-112.

Dickson, B.J., F. Sprenger, D.K. Morrison, and E. Hafen. 1992. Raf functions downstream of Ras1 in the Sevenless signal transduction pathway. Nature 360: 600-603.

Fabian, J.R., D.K. Morrison, and I. Daar. 1993. Requirement for Raf and MAP kinase function during the maturation of $\mathrm{Xe}$ nopus oocytes. J. Cell. Biol. 122: 645-652. 
Hanks, S.K., A.M. Quinn, and T. Hunter. 1988. The protein kinase family: Conserved features and deduced phylogeny of the catalytic domains. Science 241: 42-52.

Hofer, F., S. Fields, C. Schneider, and G.S. Martin. 1994. Activated Ras interacts with the Ral guanine nucleotide dissociation stimulator. Proc. Natl. Acad. Sci. 91: 11089-11093.

Kimmel, B.E., U. Heberlein, and G.M. Rubin. 1990. The homeo domain protein rough is expressed in a subset of cells in the developing Drosophila eye where it can specify photoreceptor cell subtype. Genes \& Dev. 4: 712-727.

Kornfeld, K., D.B. Hom, and H.R. Horvitz. 1995. The ksr-1 gene encodes a novel protein kinase involved in Ras-mediated signaling in C. elegans. Cell 83: 903-913.

Leevers, S.J., H.F. Paterson, and C.J. Marshall. 1994. Requirement for Ras in Raf activation is overcome by targeting Raf to the plasma membrane. Nature 369: 411-414.

Marshall, C.J. 1995. Specificity of receptor tyrosine kinase signaling: Transient versus sustained extracellular signal-regulated kinase activation. Cell 80: 179-185.

Michaud, N.R., J.R. Fabian, K.D. Mathes, and D.K. Morrison. 1995. 14-3-3 is not essential for Raf-1 function: Identification of Raf- 1 proteins that are biologically activated in a 14-3-3- and Ras-independent manner. Mol. Cell. Biol. 15: 3390-3397.

Moodie, S.A. and A. Wolfman. 1994. The 3Rrs of life: RAS, RAF and growth regulation. Trends Genet. 10: 44-48.

Moodie, S.A., B.M. Willumsen, M.J. Weber, and A. Wolfman. 1993. Complexes of Ras-GTP with Raf-1 and mitogen-activated protein kinase kinase. Science 260: 1658-1661.

Parker, P.J., L. Coussens, N. Totty, L. Rhee, S. Young, E. Chen, S. Stabel, M.D. Waterfield, and A. Ullrich. 1986. The complete primary structure of protein kinase $\mathrm{C}$, the major phorbol ester receptor. Science 233: 853-858.

Rodriguez-Viciana, P., P.H. Warne, R. Dhand, B. Vanhaesebroeck, I. Gout, M.J. Fry, M.D. Waterfield, and J. Downward. 1994. Phosphatidylinositol-3-OH kinase as a direct target of Ras. Nature 370: 527-532.

Sambrook, J., E.F. Fritsch, and T. Maniatis. 1989. Molecular cloning: A laboratory manual, 2nd edition, Cold Spring Harbor Laboratory Press, Cold Spring Harbor, NY.

Simon, M.A., D.D.L. Bowtell, G.S. Dodson, T.R. Laverty, and G.M. Rubin. 1991. Rasl and a putative guanine nucleotide exchange factor perform crucial steps in signaling by the sevenless protein tyrosine kinase. Cell 67: 701-716.

Spaargaren, M. and J.R. Bischof. 1994. Identification of the guanine nucleotide dissociation stimulator for $\mathrm{Ral}$ as a putative effector molecule of R-ras, H-ras and Rap. Proc. Natl. Acad. Sci. 91: 12609-12613.

Spradling, A.C. and G.M. Rubin. 1982. Transposition of cloned P elements into Drosophila germ line chromosomes. Science 218: 341-347.

Sprenger, F., M.M. Trosclair, and D.K. Morrison. 1993. Biochemical analysis of Torso and D-Raf during Drosophila embryogenesis: Implications for terminal signal transduction. Mol. Cell. Biol. 13: 1163-1172.

Stokoe, D., S.G. Macdonald, K. Cadwallader, M. Symons, and J.F. Hancock. 1994. Activation of Raf as a result of recruitment to the plasma membrane. Science 264: 1463-1467.

Sundaram, M. and M. Han. 1995. The C. elegans ksr-1 gene encodes a novel Raf-related kinase involved in Ras-mediated signal transduction. Cell 83: 889-901.

Therrien, M., H.C. Chang, N.M. Solomon, F.D. Karim, D.A. Wassarman, and G.M. Rubin. 1995. KSR, a novel protein kinase required for RAS signal transduction. Cell 83: 879888.

Tomlinson, A. and D.F. Ready. 1987. Cell fate in the Drosophila ommatidium. Dev. Biol. 123: 264-275.

Treisman, R. 1996. Regulation of transcription by MAP kinase cascades. Curr. Opin. Cell. Biol. 8: 205-215.

Waskiewicz, A.J. and J.A. Cooper. 1995. Mitogen and stress response pathways: MAP kinase cascades and phosphatase regulation in mammals and yeast. Curr. Opin. Cell. Biol. 7: 798-805.

Wassarman, D., M. Therrien, and G.M. Rubin. 1995. The Ras signaling pathway in Drosophila. Curr. Opin. Gen. Dev. 5: 44-50.

White, M.A., C. Nicolette, A. Minden, A. Polverino, L. Van Aelst, M. Karin, and M.H. Wigler. 1995. Multiple Ras function can contribute to mammalian cell transformation. Cell 80: $533-541$.

Wigler, M., A. Pellicer, S. Silverstein, and R. Axel. 1978. Biochemical transfer of single-copy eucaryotic genes using total cellular DNA as donor. Cell 14: 725-731. 


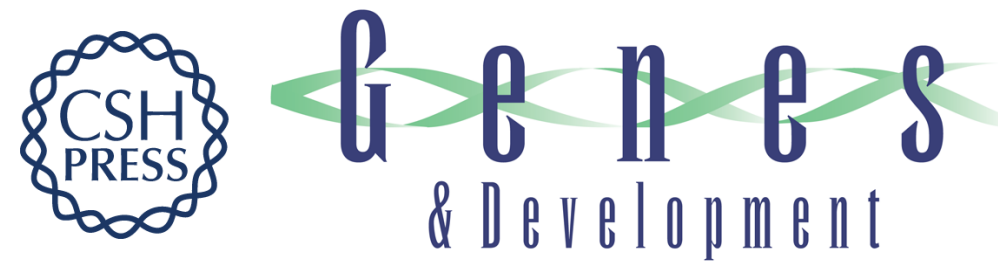

\section{KSR modulates signal propagation within the MAPK cascade.}

M Therrien, N R Michaud, G M Rubin, et al.

Genes Dev. 1996, 10:

Access the most recent version at doi:10.1101/gad.10.21.2684

References This article cites 34 articles, 15 of which can be accessed free at: http://genesdev.cshlp.org/content/10/21/2684.full.html\#ref-list-1

License

Email Alerting

Receive free email alerts when new articles cite this article - sign up in the box at the top Service right corner of the article or click here.

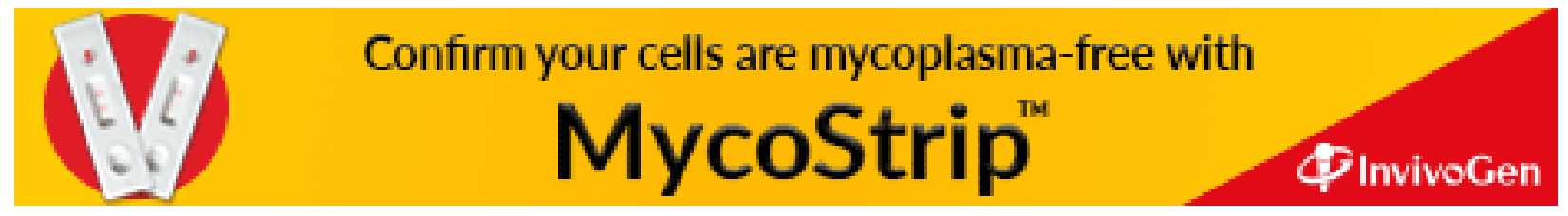

